Retrospective data from January 2020 was compared to November 2019, allowing us to establish the efficacy of changes.

Results/Conclusions October 2019 results demonstrated 59\% of patients received a FIB, this increased to $78 \%$ in January 2020. Pre-intervention, $45 \%$ of patients had the correct dose of local anaesthetic. This increased to $79 \%$ post-intervention. Initially, documentation was correct in just $5 \%$ of cases, improving to $59 \%$ after re-auditing.

Feedback from teaching sessions was positive with nursing staff better understanding the need for post-procedure monitoring. SHOs gained increased confidence delivering FIBs, freeing up senior doctors for other tasks.

The new protocol has improved the administration of FIBs with better post-procedure care and standardised dosing of local anaesthetic. Interventions are embedded in departmental practice; this will be re-audited in 6 months. Following the transition to e-noting we are developing an electronic template to translate these successes onto the new system.

\section{THE MAJOR INCIDENT APP- AN IMPROVED WAY TO CONTACT STAFF IN MAJOR INCIDENTS}

${ }^{1}$ Peter Hulme, ${ }^{1}$ Alannah Madden, ${ }^{2}$ Charlie Reynard. ${ }^{1}$ Manchester Royal Infirmary; ${ }^{2}$ University of Manchester

10.1136/emj-2020-rcemabstracts.40
Aims/Objectives/Background Major incidents are thankfully rare events but require appropriate planning and training to ensure the best response for patients and staff. The method of contacting staff in these incidents is key and needs to be quick, reliable and have excellent response times to be effective. The best method of contacting staff has not been ascertained.

The Major Incident App (MIA) is a new way to contact staff in major incidents and sends loud alerts even when phones are on silent mode. This study looks to compare the major incident response times using MIA with the previous way of contacting staff in a major incident- a freely available digital messaging platform (DMP) at Manchester Foundation Trust.

Methods/Design The decision to declare a major incident or standby was determined by the consultant in Emergency Medicine who was in the department at the time of the incident. The receiving consultants would read the message as soon as they saw it and respond appropriately. After the incidents we conducted a retrospective review of digital communication records to ascertain the time taken for a DMP or MIA message declaring an incident to be seen and read by the receiving consultants.

Reading the message within 15 minutes was regarded as an 'excellent' response time and within 60 minutes was regarded as a 'good' response. These time intervals were determined by the expert opinion of five Major Trauma consultant experts at Manchester Foundation Trust.

\begin{tabular}{|c|c|c|c|c|c|c|c|}
\hline Incident Type & Date & Time & Day of the week & $\begin{array}{l}\text { Ave Response } \\
\text { time mins }\end{array}$ & $\begin{array}{l}\text { Median response } \\
\text { times mins }\end{array}$ & $\begin{array}{l}\text { Seen within } 15 \\
\text { mins (\%) }\end{array}$ & Seen within $1 \mathrm{hr}(\%)$ \\
\hline Simulated & $29 / 3 / 17$ & $10: 38$ & Wednesday & 76.6 & 30 & $9 / 25(36 \%)$ & $15 / 25(60 \%)$ \\
\hline Manchester Arena Attack & $22 / 5 / 17$ & $22: 55$ & Monday & 99.3 & 9.5 & $15 / 26(57.6 \%)$ & $20 / 26(76.9 \%)$ \\
\hline Simulated & $16 / 9 / 17$ & $10: 40$ & Saturday & 79.9 & 10 & $18 / 23(78.2 \%)$ & $22 / 23(95.6 \%)$ \\
\hline City centre Fire & $30 / 12 / 17$ & $17: 29$ & Saturday & 30.5 & 8 & $17 / 25(68 \%)$ & $21 / 25(84 \%)$ \\
\hline Simulated & $18 / 9 / 18$ & 09:35 & Tuesday & 17.8 & 4 & $19 / 24(79.1 \%)$ & $22 / 24(91.7 \%)$ \\
\hline Multiple Stabbing & $11 / 10 / 19$ & 12:05 & Friday & 86.5 & 33.5 & $11 / 28(39.2 \%)$ & $16 / 28(57.1 \%)$ \\
\hline Chemical Incident & $11 / 10 / 19$ & $13: 46$ & Friday & 56.5 & 21.5 & $9 / 26(34.6 \%)$ & $20 / 26(76.9 \%)$ \\
\hline Multiple Stabbing & $15 / 10 / 19$ & $16: 46$ & Tuesday & 23.9 & 11 & $15 / 27(55.5 \%)$ & $25 / 27(92.6 \%)$ \\
\hline New Years Eve multiple traumas & $1 / 1 / 20$ & $04: 14$ & Wednesday & 184.3 & 219 & $4 / 26(15.3 \%)$ & $6 / 26(23 \%)$ \\
\hline Overall & & & & & & $117 / 230(50.8 \%)$ & $167 / 230(72.6 \%)$ \\
\hline
\end{tabular}

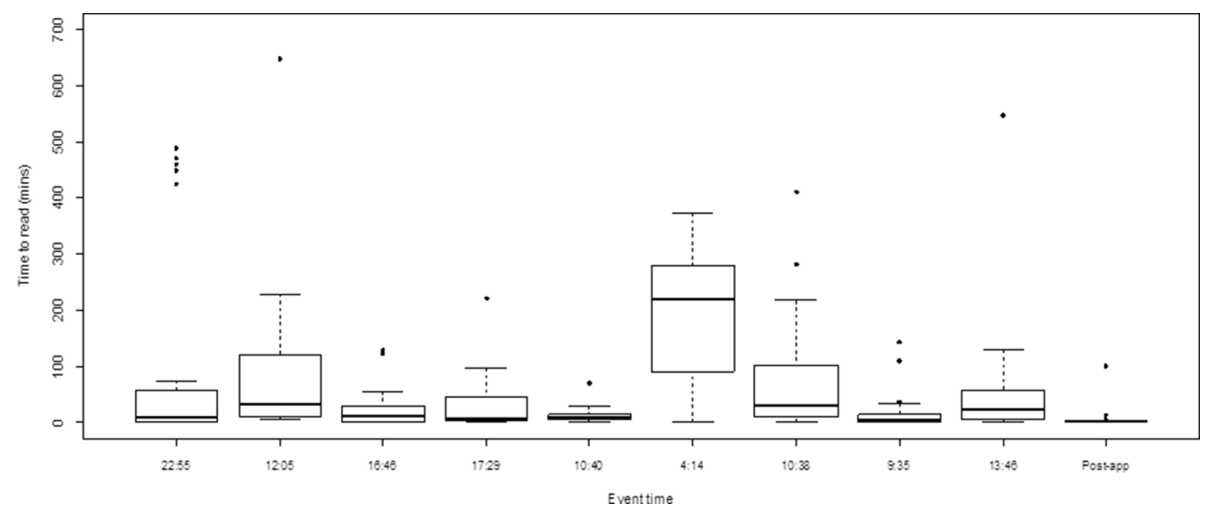

Abstract 134 Figure 1 


\section{MAJOR INCIDENT APP}

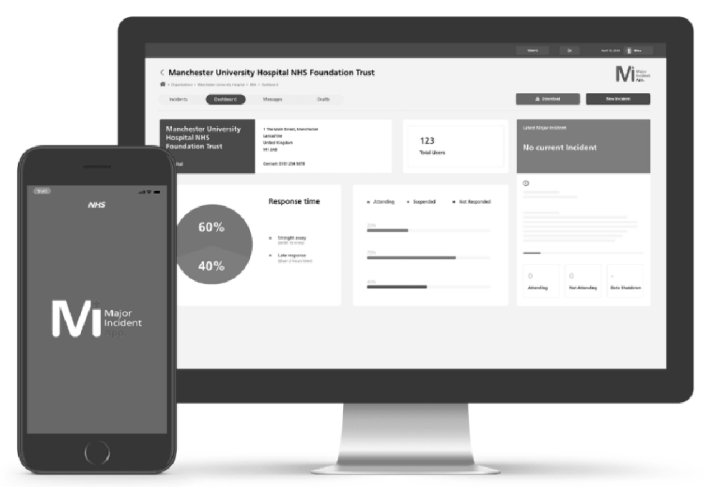

Abstract 134 Figure 2

\begin{tabular}{|c|c|c|c|c|c|c|c|}
\hline $\begin{array}{l}\text { Incident } \\
\text { Type }\end{array}$ & Date & Time & $\begin{array}{l}\text { Day of } \\
\text { the } \\
\text { week }\end{array}$ & $\begin{array}{l}\text { Ave } \\
\text { Response } \\
\text { time mins }\end{array}$ & $\begin{array}{l}\text { Median } \\
\text { response } \\
\text { times mins }\end{array}$ & $\begin{array}{l}\text { Seen } \\
\text { within } 15 \\
\text { mins (\%) }\end{array}$ & $\begin{array}{l}\text { Seen } \\
\text { within } \\
1 \mathrm{hr}(\%)\end{array}$ \\
\hline $\begin{array}{l}\text { City } \\
\text { Centre } \\
\text { fight }\end{array}$ & $31 / 5$ & $20: 54$ & Sunday & 1.3 & 1 & $\begin{array}{l}22 / 22 \\
(100 \%)\end{array}$ & $\begin{array}{l}22 / 22 \\
(100 \%)\end{array}$ \\
\hline
\end{tabular}

A Wilcoxon rank sum test was used to compare the two methods.

Results/Conclusions Response times were significantly better with MIA compared to DMP p-value $<0.001$ (see Tables 1 and 2) and all messages were seen within 4 minutes. Although the numbers of incidents are small, this study shows that incident response times can be significantly improved with the MIA that alerts phones in silent mode.

\section{A CLOSED LOOP AUDIT ON OXYGEN PRESCRIPTION IN THE EMERGENCY DEPARTMENT IN IPSWICH HOSPITAL}

Ellhia Sudin, Devraj Kathwadia, Eddie Udofa, Abhijit Bose. Ipswich Hospital

\subsection{6/emj-2020-rcemabstracts. 41}

Aims/Objectives/Background The British Thoracic Society (BTS) produced the world's first guidelines on oxygen therapy in the emergency setting in 2008, with subsequent updates in 2017. The key recommendation was that oxygen should be prescribed with target saturations tailored to individual patients.

Whilst most clinicians appreciate the dangers of under-oxygenation, there is a lesser regard for the dangers of over-oxygenation. This is particularly important in certain conditions which may predispose to hypercapnic respiratory failure and acidosis.

We therefore set out to assess compliance to the BTS guidelines, and to educate clinicians on the importance of good oxygen prescribing practice.
Methods/Design The first cycle was conducted in August 2019. The results were presented in a series of departmental teaching sessions, along with the BTS recommendations and the importance of good oxygen prescribing practice. The second cycle was later conducted in April 2020.

For each cycle, we randomly selected records of 50 adult patients who either: (1) arrived with oxygen saturations less than 93\%; or (2) were already on oxygen on arrival to the emergency department. For each record, we assessed whether the target oxygen saturations were prescribed.

Results/Conclusions A total of 100 patients were included in this study. Prior to the departmental teaching sessions, only $14 \%$ of patients had target oxygen saturations prescribed. The teaching sessions on oxygen prescription resulted in a small but statistically non-significant improvement in oxygen prescription to $20 \%(\mathrm{p}=0.595)$.

This study shows that departmental teaching sessions alone are not sufficient to improve compliance with oxygen prescribing practice. Further efforts are required to change ingrained behaviours and culture, particularly in settings such as the emergency department with high rates of clinician turnover and ad-hoc locum cover. Further recommendations to facilitate these changes will require engagement from the multidisciplinary team, such as prompting from the nursing team, and spot checks by senior clinicians.

\section{CURRENT PROVISION OF GENERAL PRACTITIONER SERVICES IN OR ALONGSIDE EMERGENCY DEPARTMENTS IN ENGLAND}

${ }^{1}$ Heather Brant, ${ }^{1}$ Sarah Voss, ${ }^{2}$ Alison Cooper, ${ }^{2}$ Michelle Edwards, ${ }^{2}$ Delyth Price, ${ }^{3}$ James Gaughan, ${ }^{2}$ Adrian Edwards, ${ }^{1} J o n a t h a n$ Benger. ${ }^{1}$ UWE Bristol; ${ }^{2}$ Cardiff University; ${ }^{3}$ University of York

\subsection{6/emj-2020-rcemabstracts.42}

Aims/Objectives/Background One approach to addressing increasing demand in emergency departments (EDs) has been the co-location of general practitioners (GPs) in or alongside the emergency department (ED), known as GPED. This approach was both advocated by the National Health Service (NHS) and supported by capital funding in 2017. However, little is known about the models of GPED that have been implemented as a result.

Methods/Design We collected data on the model of GPED in use (if any) at 163/177 (92\%) of type one EDs in England at two time points: September 2017 and December 2019. Multiple data sources were used including: on-line surveys; interviews; case study data; publicly available information. Models were classified according to an iteratively developed taxonomy as Inside/integrated, Inside/parallel, Outside/onsite, Outside/ offsite.

Results/Conclusions The proportion of EDs using GPED increased from $81 \%$ to $95 \%$ over the study period. The most common model was 'Inside/parallel' to the ED: 30\% (44/149) in 2017 , rising to $49 \%(78 / 159)$ in 2019 . The number of Inside/integrated models dropped from $26 \%$ (38/149) to $9 \%$ (15/159). 23 sites commenced and four sites ceased GPED provision. $87 \%(142 / 163)$ of the EDs sampled were awarded capital funding. We identified no association between the type of GPED model adopted and the observable characteristics of EDs such as annual attendance, rurality of location and deprivation within the population served. 